\title{
Jordanian University Students' Use of English: Urban-Rural Dichotomy and University Location
}

\author{
Reema Salah \\ Department of English, Faculty of Art and Humanities, Al al-Bayt University, Al Mafraq, Jordan \\ Email: dr.reema.salah@aabu.edu.jo
}

How to cite this paper: Salah, R. (2021). Jordanian University Students' Use of English: Urban-Rural Dichotomy and University Location. Advances in Literary Study, 9, 105-113.

https://doi.org/10.4236/als.2021.93012

Received: March 10, 2021

Accepted: May 25, 2021

Published: May 28, 2021

Copyright $\odot 2021$ by author(s) and Scientific Research Publishing Inc. This work is licensed under the Creative Commons Attribution International License (CC BY 4.0).

http://creativecommons.org/licenses/by/4.0/

\section{(c) (i) Open Access}

\begin{abstract}
Second language users use the language for various reasons. Three reasons are examined in this paper: linguistic, social, and academic. A sample of Jordanian students from three universities in Jordan was asked to complete a survey about their use of English $(N=1052)$. A 2 gender (male, female) $\times 2$ dwelling (urban, rural) $\times 3$ university locations multivariate analysis of variance (MANOVA) found significant main effects of gender on the linguistic social factor. No interaction effect was significant. The results show that male students tend to feel more linguistically competent than females, but females tend to use English for social reasons more often than males. Students who live in a city tend to use English more than those living in a village when they use the language for linguistic or academic purposes.
\end{abstract}

\section{Keywords}

University's Students, English Use, Urban-Rural Dichotomy, Second Language Learning, English-Arabic Contact

\section{Introduction}

Second language (L2) learners have various reasons for learning and using the language. In this paper, the researcher examined three possible reasons for Arabic-speaking Jordanians mixing English with Arabic: linguistic, social and academic. The sample of students came from three universities in North Jordan, who were asked to complete a survey about their use of English. The aim of the study was to examine: 1) whether the three reasons can be differentiated as three distinct factors that affect Jordanian university students' use of English in an Arabic-speaking environment, and 2) whether students' gender, place of living, 
and place of study matter in affecting their use of English language.

\section{English as a Second Language in Jordan}

Throughout the Arab World, Standard Arabic is designated as the official language, the medium of instruction in education, and the language of mass media. However, in actual practice in daily life, a mixture of both standard and colloquial varieties is used in education and in the media (Al-Wer, 2005). In addition to the Arabic language, English language has become a significant component in the school curriculum. While Arabic remains the official language in Jordan, English has been taught in Jordan's schools and universities since the independence of Transjordan as a Kingdom (Milton-Edwards \& Hinchcliffe, 2001). Although English is neither a national nor an official language, it is the most widely taught foreign language in the country (Al Saidat, 2009). Today, many people use English in their Jordanian Arabic speech. They include educators and students undertaking higher education where English is either mixed with Arabic or is the major language used, particularly in some specific disciplines. For example, English is generally recognized as the language of science and technology at university level and among educated people in their professional capacities. Some disciplines such as medicine, engineering, nursing, and many others are mostly taught in English (Mubaidin, 2010).

English is gaining increasing popularity in Jordan, and English language teaching is further encouraged by the British Council, which was established two years after Jordan's independence. Currently, there are many Jordanian newspapers published in English, such as Jordan Times and The Stars. Jordan Radio and Television provide services in Arabic, English and French. Jordan being a member of many English-speaking international organizations, Jordanians are likely to have a strong motivation to learn English. English is widely used as a tool for various purposes ranging from highly specialized activities to casual exchanges with foreigners in public places (Bani Abdelrahman, 2003). The ability to use English is important because, as Al Taweel (2005) has noted, it "guarantees more job opportunities; it means having more access to more work places and education sectors, entertainment facilities, reading, and so on" (p. 4). As such, a social factor which encourages Jordanians to learn English and to speak it in public is the prestigious status associated with it.

\subsection{Reasons for Using English}

Many Jordanians seem to be motivated to learn and use English in their speech, and there may be various reasons for this. Some of the reasons are related to the language itself whereas some others may be "non-language factors" (Duan, 2011). This paper focuses on three major factors: linguistic competence, social status and academic such as science-related contexts (referred to as: linguistic, social, and academic).

Linguistic. Research has shown that one of the strongest predictors of per- 
formance and behaviour is the individual's self-beliefs of competence (Marsh \& Yeung, 1997; Ryan \& Deci, 2000). For example, a high self-concept in English leads to students' better performance and higher test scores in English (Craven \& Yeung, 2008). A sense of competence therefore predicts one's achievement and language choice in a relevant area such as English use, and also influences one's sense of identity (Yeung, Craven, \& Kaur, 2012).

Social. Jordanians' perceived social status associated with the ability to use English is quite obvious. This is not surprising given the opportunities the language is associated with: employment, further education, and affiliation with international business partners ( $\mathrm{Al}$ Taweel, 2005). English-speaking people in Jordan seem to be generally more educated, wealthier, and hold higher ranks in employment. Hence, one major reason for Jordanians to use English is a social factor due to the perceived prestigious status associated with it. Nevertheless, Jordanians often look for cues such as education, occupational prestige, and setting before determining to use English in an acceptable way (Heckenlaible, 2012).

Academic. Examining Jordanian identity through language, Pedersen (2010) found that many participants find English closely aligned with the technology. English words and phrases are commonly used when the content of the discourse is related to science and technology or academic issues (Al-Khatib \& Sabbah, 2008). Some of the technical terms used by students include: modem, hardware and software. English is also used to refer to courses such as physics, pharmacy, advanced electronics, dentistry, or herbal medicine. This can be attributed to the fact that such scientific lectures in Jordanian universities are mostly delivered in English. Therefore, the English-based academic atmosphere in Jordanian universities may have promoted students' use of English terms when talking about university and academic issues.

\subsection{Who Uses English}

For Jordanians to use English for any of the three reasons: linguistic, social, and academic, there may be various influential factors. The language users' gender, the place of living, and the location of the university where the language user studies may be significant factors that influence their reasons of English use.

Gender issues. For linguistic competence, it is well documented in psychological research that females tend to have significantly higher self-perceptions of verbal competence than males (e.g., Marsh \& Yeung, 1998). Based on the higher potential of individuals having a positive self-concept in using English (Craven \& Yeung, 2008), we may expect females to use English due to their higher self-perception of linguistic competence in English. For social status as a major reason of language use, there is no clear evidence for a well-defined hypothesis. First, to the extent that males dominate institutions, one might expect them to be more engaged in the foreign language market. Second, one of the popular generalizations about male and female speech is the common claim that women's speech is more conservative than men's. In general, women are more statusconscious and polite than men who are more rough and down-to-earth (Eckert, 
2011). However, in modern Jordan, males and females may use a mix of standard Arabic and English, depending on the social situation. For academic reasons, there is unlikely to be any gender difference. When the academic is well defined such that English is the generally accepted language in that specific field and the Arabic language is not considered adequate for the functional purpose of communication, it is natural for both genders to use English instead of Arabic.

Urban and rural L2 learners. Considering the effect of place of living upon the use of English among Jordanians, Bader (1995) found that city residents use English more than village residents. He distinguishes between two sub-categories of city residents: those coming from rich areas and those coming from less privileged areas. The results of his study show that the first group use English more than the second one. He explains that the more frequent English use among the first group is because "better economic and social conditions lead to higher education" (p. 17). However, this is not the case anymore in Jordan, as people from average and poor socioeconomic backgrounds are increasingly interested in education nowadays, whereas young people from affluent families do not need to worry about their future. Nevertheless, as Bader argues, there is a strong positive correlation between the use of English and features such as: city-residents, well educated, young and female, as opposed to their counterparts: villagers, illiterate, old, and males. In any case, Hussein (1999) reinforces that educated people and those who learn or have learned English use English more than those who do not. As city-dwellers are more likely to be exposed to English, it is possible that people who live in the city have higher self-perceptions of English competence, use English to show their social status, and use technical terms in English when talking about science and technology.

\subsection{Location of University}

In his research Arabic-English Code-Switching Among American Fastfood Restaurants' Employees and Customers in Jordan: Motivations and Attitudes, Hleihil (2001) concludes that participants who live or work in Amman tend to use English more often than those who live or work in Zarqa or Irbid while discussing work matters. This phenomenon may be due to the high level of education of the people who work or deal with such restaurants [located in Amman, the capital city of Jordan], or may be due to the factor of prestige (p. 57).

This not only reflects that place of living is a strong determining factor for use of English. It also suggests that students who study in a university in the capital city may use English more than those in less modern and vibrant cities. However, because of modern information technology and the much improved mobility of people in rural areas, the difference between universities in urban and rural regions may be minimal. To examine any potential difference due to the location of students' place of study, three universities were chosen in this study. Al Al-Bayt University, Yarmouk University, and the University of Jordan are three of the oldest public universities in North Jordan. Whereas the University of Jordan is located in the capital city, the other two are located in less vibrant cities 
with fewer foreigners. However, since they are public universities receiving equal public financial support, there is unlikely to be a huge gap in the students' socioeconomic backgrounds.

\section{The Present Study}

In the present investigation, students from three universities in North Jordan were asked to complete a survey about their use of English. It was hypothesized that three major reasons for using L2 English would be clearly distinguishable as separate purposes. It was also hypothesized that gender differences exist favoring females when L2 English use was related to linguistic competence. Between city and village dwellers, students who lived in a city were expected to use English more than those living in a village. However, students from different universities may not differ much, although students attending a university in the capital city may have better opportunities of L2 applications and may perhaps perceive higher competence in the L2 than students from other universities. The analysis would also test this possibility.

\section{Method}

\subsection{Participants}

The participants were students from three universities: Al al-Bayt University, Yarmouk University and the University of Jordan, total $N=1052$ for the analysis. These are the oldest public universities in North Jordan, located within 100 $\mathrm{km}$. Because of their proximity and similarity, the students in these universities are likely to display similar linguistic behaviors.

\subsection{Material and Procedure}

University ethics procedures were followed. The students responded to items printed on a survey (see example items in Figure 1). Their response to the survey was voluntary and anonymous. The items asked about three possible purposes of using English in their everyday life: 1) linguistic (5 items: e.g., I use English spontaneously and unconsciously), 2) academic (4 items: e.g., It is easier to express scientific concepts in English), and 3) social (4 items: e.g., I use English in my speech to show my social status). The survey also asked about their background such as gender, place of living, and social economic status, etc.

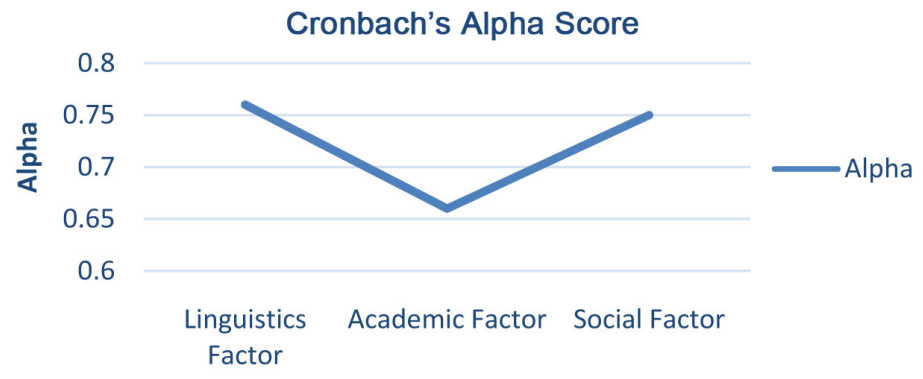

Figure 1. Response items and alpha reliabilities of scales. 


\subsection{Analysis}

The participants' responses on a five-point scale were coded such that $1=$ low to $5=$ high. Alpha reliability was estimated for each of the three factors (linguistic, academic, and social). Principal component analysis was conducted to test the ability of the items to establish the three factors. Correlation analysis was conducted with the factor scores (an average of the item scores pertaining to the respective factor) to examine the associations among the three factors. Using the factor scores, a 2 (gender) $\times 2$ (dwelling: urban, rural) $\times 3$ (universities) multivariate analysis of variance (ANOVA) was conducted. The purpose was to examine whether there was any significant difference in the purposes of using English for these factors and their interactions.

\section{Results and Discussion}

The factors had acceptable reliabilities (alphas $=.76, .66$, and .75 for linguistic, academic, and social, respectively). The means, standard deviations, and reliability estimates for each factor are presented in Figure 1. Figure 2 presents the results of the principal component analysis and correlations among the three factors. Three factors were found explaining $53.64 \%$ of total variance. The factor loadings were good for the items expected to be loading on the respective factor (ranging from .52 to .83 ). The three factors had low to medium correlations among them (rs from .08 to .48), showing that they were clearly distinguishable from one another. Hence these preliminary analyses found that the students had clearly differentiated purposes when they used English in their daily life. In essence, our hypothesis was supported in that the three major reasons for using L2 English were clearly distinguishable as separate purposes.

Figure 3 presents the means, standard deviations, and the F-statistics of the 2 (gender) $\times 2$ (dwelling) $\times 3$ (universities) multivariate ANOVA. The ANOVA found statistically significant main effects of gender and dwelling for the linguistic purpose, Fs $(1,1040)=5.38$ and 8.88 , respectively, $p<.05$; but the main effect of university was not significant Fs $(2,1040)=2.52$. An inspection of the mean scores found that female students tended to be higher than males for the linguistic factor, whereas students living in the village tended to be higher than those living in the city. Universities did not differ for the linguistic purpose, nor for the academic and social purposes (Figure 3). Hence the results supported our hypothesis that some gender differences would exist and that females tended to use L2 English for reasons related to their linguistic competence.

For the academic purpose, the main effect of dwelling was statistically significant, Fs $(1,1040)=6.00, p<.05$, indicating that students living in the village tended to use English more than those living in the city for academic purposes. The main effects of gender and university were not significant Fs $=0.60$ and 0.98, respectively (Figure 3). However, all differences for the linguistic and academic factors were found to be small with $\eta^{2}=.01$ for the statistical effects, and $\eta^{2}=.00$ for non-significant effects. 


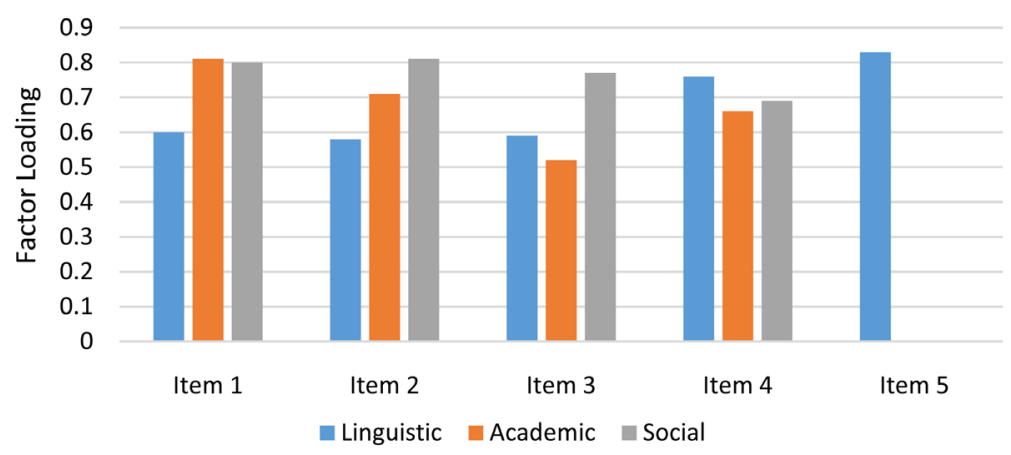

Figure 2. Factor loadings.

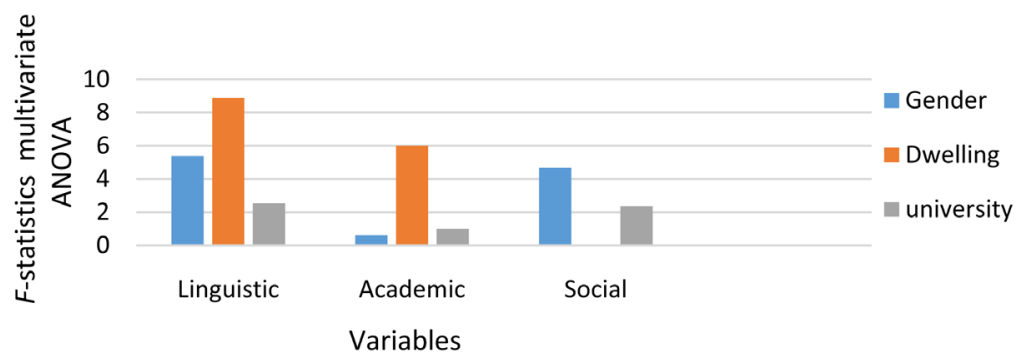

Figure 3. 2 (Gender) $\times 2$ (Dwelling) $\times 3$ (University) ANOVA results.

For the social purpose, the main effect of gender was statistically significant, Fs $(1,1040)=4.68, p<.05$, indicating that male students seemed to use more English for social purposes than females. Neither main effects of dwelling and university was significant $F s=0.00$ and 2.35 , respectively (Figure 3 ). All these effects were very small with $\eta^{2}=.00$ even for the statistically significant effect of gender. Hence the differences found for social purpose may not have any practical implication.

All interaction effects were not statistically significant ( $\mathrm{ps}>.05$ ), and are reported here for completeness. The gender $\times$ dwelling effects for linguistic, academic, and social purposes were: Fs $(1,1040)=0.57,0.00$, and 0.41 , respectively; the gender $\times$ university effects were: Fs $(2,1040)=1.66,0.76$, and 0.39 , respectively; the dwelling $\times$ university effects were: Fs $(2,1040)=1.44,0.93$, and 0.10 , respectively. Finally, the 3 -way gender $\times$ dwelling $\times$ university effects were: Fs $(2$, $1040)=0.31,0.76,1.63$, respectively. All $\eta^{2}=.00$.

In the present investigation, students from three universities in North Jordan were asked to complete a survey about their use of English. It was hypothesized that three major reasons for using L2 English would be clearly distinguishable as separate purposes. It was also hypothesized that differences exist favoring each gender when considering three purposes of English use in the Jordanian context. The results show that males tend to use English for a social purpose more often than females who tended to be higher than their counterpart for the linguistic purpose. Between city and village dwellers, students who lived in a city were expected to use English more than those living in a village. However, students from different universities may not differ much, although students attending a uni- 
versity in the capital city may have better opportunities of L2 applications and may perhaps perceive higher competence in the L2 than students from other universities. The analysis would also test this possibility.

\section{Conclusion}

The results of the analyses have important implications for Arabic-English contact in Jordan. University students are usually aware that in certain situations they can be more favorably valued by their interlocutors if they use more prestigious forms in their speech. English is the language that can be used only by those who are highly educated and who are ranked highly on the social strata of Jordanian society (Al Khatib \& Farghal, 1999; Al-Khatib \& Sabbah, 2008). The result was also supported by al Hayek (2016) whose study results showed that Jordanian-university students have positive attitudes to English-language speakers who are seen as favorably valued by their interlocutors when using such prestigious linguistic form [English language].

\section{Conflicts of Interest}

The author declares no conflicts of interest regarding the publication of this paper.

\section{References}

Al Hayek, R. S. (2016). Arabic-English Code-Mixing by Jordanian University Students. Doctoral Dissertation, Sydney: Western Sydney University.

Al Saidat, E. (2009). English in Jordan: Attitudes and Prestige. Indian Journal of Applied Linguistics, 35, 155-167

Al Taweel, A. (2005). Gender Representation in Twelfth Grade English Language Textbooks in High Schools in Jordan. Doctoral Dissertation, Tempe, AZ: Arizona State University.

Al-Khatib, M. A., \& Farghal, M. (1999). English Borrowing in Jordanian Arabic: Distribution, Functions, and Attitudes. Grazer Linguistische Studien, 52, 1-18.

Al-Khatib, M., \& Sabbah E. (2008). Language Choice in Mobile Text Messages among Jordanian University Students. SKY Journal of Linguistics, 21, 37-65.

Al-Wer, E. (2005). Variation in Arabic Languages. In K. Brown (Ed.), Encyclopedia of Language and Linguistics (2nd ed., pp. 341-344). Amsterdam: Elsevier. https://doi.org/10.1016/B0-08-044854-2/01527-3

Bader, Y. (1995). Code-Switching to English in Daily Conversations in Jordan: Factors and Attitudes. Abhath Al Yarmouk: Lit \& Ling, 13, 9-27.

Bani Abdelrahman, A. (2003). The Effectiveness of the English Language/Field Teacher Preparation Program at Yarmouk University in Jordan as Perceived by Its Students. Doctoral Dissertation, Fayetteville, AR: University of Arkansas.

Craven, R. G., \& Yeung, A. S. (2008). International Best Practice in Effective Educational Interventions: Why Self-Concept Matters and Examples from Bullying, Peer Support, and Reading Research. In D. M. McInerney, V. E. Shawn, \& M. Dowson (Eds.), Research on Sociocultural Influences on Motivation and Learning. Vol. 8: Teaching and Learning: International Best Practice (pp. 267-294). Charlotte, NC: Information Age Publishing. 
Duan, Y.-B. (2011). How to Motivate Students in Second Language Writing. Sino-US English Teaching, 28, 235-240.

Eckert, P. (2011). Gender and Sociolinguistic Variation, In J Coates, \& P. Pichler (Eds.), Language and Gender (2nd ed.). Hoboken, NJ: Wiley-Blackwell.

Heckenlaible, V. (2012, March 30). Arabic-English Codeswitching: Negotiating Social Networks in Jordan. Undergraduate Conference Program on Language Variation and Language Contact, The University of Texas at Austin. http://hdl.handle.net/2152/15560

Hleihil, H. (2001). Arabic-English Code-Switching among American Fast-Food Restaurants' Employees and Customers in Jordan: Motivations and Attitudes. Master's Thesis, Irbid: Yarmouk University. http://repository.yu.edu.jo/handle/123456789/5504

Hussein, R. F. (1999). Code-Alteration among Arab College Students. World Englishes, 18, 281-289. https://doi.org/10.1111/1467-971X.00141

Marsh, H. W., \& Yeung, A. S. (1997). Coursework Selection: Relations to Academic Self-Concept and Achievement. American Educational Research Journal, 34, 691-720. https://www.jstor.org/stable/1163354 https://doi.org/10.3102/00028312034004691

Marsh, H. W., \& Yeung, A. S. (1998). Longitudinal Structural Equation Models of Academic Self-Concept and Achievement: Gender Differences in the Development of Math and English Constructs. American Educational Research Journal, 35, 705-738. https://doi.org/10.3102/00028312035004705

Milton-Edwards, B., \& Hinchcliffe, P. (2001). Jordan: A Hashemite Legacy. Abingdon-on-Thames: Routledge.

Mubaidin, A. F. (2010). Neurological Letter from Jordan. Practical Neurology, 10, 112-113. https://doi.org/10.1136/jnnp.2009.203927

Pedersen, A. (2010). Negotiating Cultural Identities through Language: Academic English in Jordan. College Composition and Communication, 62, 283-310. http://www.jstor.org/stable/27917897

Ryan, R. M., \& Deci, E. L. (2000). Intrinsic and Extrinsic Motivations: Classic Definitions and New Directions. Contemporary Educational Psychology, 25, 54-67. https://doi.org/10.1006/ceps.1999.1020

Yeung, A. S., Craven, R. G., \& Kaur, G. (2012). Mastery Goal, Value, and Self-Concept: What Do They Predict? Educational Research, 54, 469-482.

https://doi.org/10.1080/00131881.2012.734728 